\title{
$\widehat{A}$ Madridge
}

madridge Journal of Women's Health and Emancipation

interconnecting Scientfic World

Research Article

Open Access

\section{Evaluation of a Collegiate Women's Sexual Health Promotion and Education Program}

\author{
Caroline Baumann, Jessica Naber* and Michael Perlow \\ School of Nursing and Health Professions, Murray State University, Murray, KY 42071, USA
}

\section{Article Info}

\author{
"Corresponding author: \\ Jessica Naber \\ Assistant Professor \\ School of Nursing and Health Professions \\ Murray State University \\ Murray, KY 42071 \\ USA \\ Tel: 502-541-3011 \\ E-mail: jnaber@murraystate.edu
}

Received: March 1, 2016

Accepted: May 21, 2016

Published: January 5, 2017

Citation: Baumann C, Naber J, Perlow M. Evaluation of a Collegiate Women's Sexual Health Promotion and Education Program Madridge J Womens Health Emancipation. 2017; 1(1): 1-3.

doi: 10.18689/mjwh-1000101

Copyright: @ 2017 The Author(s). This work is licensed under a Creative Commons Attribution 4.0 International License, which permits unrestricted use, distribution, and reproduction in any medium, provided the original work is properly cited.

Published by Madridge Publishers

\begin{abstract}
The purpose of this study was to provide a Women's Sexual Health Promotion and Education program to teach female college students about gynecology, the menstrual cycle, the female reproductive system, Sexually Transmitted Infections (STIs), and pregnancy prevention. The program's success was measured using a pre-test and a post-test. A t-test analysis confirmed a significant increase in participant knowledge of women's sexual health as a result of the program. This program may serve as a guideline for future women's sexual health programs and adds to current research supporting the need for more sexual health education programs.
\end{abstract}

Keywords: Women's sexual health; Education program; Self-awareness; Sexual partners.

Abbreviations: STIs: Sexually Transmitted Infections; ACHA-NCHA: American College Health Association National College Health Assessment; HPV: Human Papillomavirus; IUD: Intrauterine device

\section{Introduction}

In order to protect themselves from select health care issues, college age females need to possess knowledge about themselves, their bodies, and their behavior. Research indicates an overall need for an increase in this knowledge, as discussed in the literature review. To better understand the effect of education on self-awareness, a study was conducted offering a women's sexual health promotion and education program on campus at a mid-size regional public university to all interested female students. This article describes the need for programs such as this one at other universities and among this population of females.

\section{Literature Review}

According to the American College Health Association National College Health Assessment (ACHA-NCHA, 2006) [1] sexually active female participants had an average of 1.8 sexual partners. When male and female students were asked about their use of pregnancy protection methods $4 \%$ used nothing, $15 \%$ used the withdrawal technique, $35 \%$ used birth control pills, $36 \%$ used condoms, and $28 \%$ said they had not had intercourse.

The fall 2009 ACHA-NCHA [2] survey reveals, $48.7 \%$ of female college students had not seen a gynecologist in the past year. In the past 30 days $60.9 \%$ had not performed a breast self-exam. As reported by both males and females, $51.3 \%$ had not received information about STIs and $63.7 \%$ about pregnancy at their school. Thirty percent reported an interest in receiving pregnancy prevention information and $38.1 \%$ in receiving STI information (ACHA-NCHA, 2009). Paul, McManus, and Hayes (2000) 
surveyed sexually risky behaviors of college students [3]. Of the 555 participants, 169 participants had "hooked-up" with a partner at least once.

The fall 2015 ACHA-NCHA [4] survey shows continued trends in sexual health education needs. Only $48.2 \%$ of female college students received the vaccination against Human Papillomavirus (HPV). $37.4 \%$ of females reported performing a breast self exam in the last 30 days, and $42.4 \%$ had a routine gynecological exam in the last 12 months. In terms of pregnancy protection used by females or their partners, $57.2 \%$ used birth control pills, 4.1\% used birth control shots, 5.2\% used implants, 9.0\% used intrauterine devices, $8.5 \%$ used the calendar method or other methods of fertility awareness, $34.8 \%$ used withdrawal, and $59 \%$ used male condoms. Other lesser used methods included birth control patches, female condoms, diaphragms, cervical caps, contraceptive sponges, and spermicides.

According to Calco (2014), nearly $50 \%$ of STI's occur between the ages of 15 and 24, putting traditional undergraduate college students in the ideal age range for receiving sexual health education. However, $42 \%$ of participants did not consider themselves knowledgeable about STIs [5-8]. Oster (2015) discussed high risk behaviors of college students [9]. These included inconsistent condom use during vaginal or anal sex, multiple partners, alcohol and drug use before and during sexual activity. These behaviors increase the risk for HIV and other STIs and unintended pregnancy.

\section{Methods}

This study used a pre-experimental pre-test, post-test design. The 19 participants were 18 to 25 year old female students who attended the two hour program at a mid-size, regional public university. Approval of human subjects protection was granted by the home institution's IRB. All participants signed informed consent forms before the program began. A pre-test and post-test included fifteen multiple choice questions that surveyed participant knowledge in the topics of STIs, pregnancy prevention, gynecology, female reproductive anatomy, and the menstrual cycle. The questionnaires also examined sexual protective habits and an understanding of women's health. After the pre-test, the researcher presented an hour-long program that included information about the topics from the pre-test. The program was a combination lecture-discussion style. Immediately following the program, the post-test was administered, and the post-test also provided an opportunity for evaluation of the program. A T-test analysis of the pre-test and post-test scores evaluated if the student's educational needs were met. Finally, participant opinions regarding the program were sought.

\section{Results}

Results from the paired t-test analysis revealed a statistically significant difference between pre-test and posttest scores ( $t=10.88 ; D F=18 ; x=3 ; S x=1.2 ;$ and $p<0.001)$. The mean score of the fifteen question test was $0.57(=8.5 / 15)$ on the pre-test and $0.77(=11.5 / 15)$ in the post-test. Participants' self-report rating of their understanding of the menstrual cycle and female reproductive anatomy improved from pretest to post-test.

The pre-test and post-test were used to obtain information regarding participant sexual habits and attitudes. Ten of 19 participants reported being sexually active on the pre-test and nine reported being sexually active on the post-test. No participants reported feeling at risk for acquiring STIs and two reported feeling at risk for pregnancy on the pre-test and post-test. One participant reported an unwanted or unplanned pregnancy, and one reported being diagnosed with an STI. Thirteen participants, who could respond to more than one choice, reported previously being to the gynecologist; ten went for well-woman check-ups, two for suspected pregnancy, two for a suspected STI, eight to be get birth control, and two for other purposes. When asked about plans to see the gynecologist within the year, 14 participants responded yes on the pre-test and 15 responded yes and one responded may be on the post-test.

The participants were questioned about sexual protective habits regarding pregnancy and STI prevention. Concerning pregnancy prevention methods, 7 participants reported use of abstinence, 10 used oral contraceptives, 7 used condoms, 3 used the "pulling out" technique, and two reported using no method. Regarding STI prevention, 8 reported abstinence, 4 used oral contraceptives, 8 used condoms, 1 used the "pulling out" technique, and 3 used no method. Five participants also reported the use of abstinence for medicinal purposes, 9 used the pill for medicinal purposes, and 6 reported no method for medicinal purposes. According to Oster (2015), college students are likely to take part in the same risky behaviors such as using the pulling out technique, lack of condom use, and using no contraceptive method.

In addition, the participants were queried regarding their opinions of the program. Participant ratings confirmed overall positive opinions. The identified strengths of the program were information about pregnancy prevention and gynecology while the weakness was students' comfort level with the topic during the program. Participants expressed a desire for a similar program in the future. Participants also rated benefits of the program as follows; the ease of understanding the information about STIs, the female reproductive system, and the menstrual cycle.

\section{Discussion}

The Women's Sexual Health Promotion and Education Program was effective in increasing the knowledge of the participants. Every participant's score improved an average of three questions. The results supported that women's sexual health education could be an effective means of increasing the population's knowledge of women's health issues.

The participant's scores revealed an awareness of STI prevention, breast self-examinations, the ovaries, and factors 
affecting the menstrual cycle. Calco's (2014) participants, on the other hand, expressed a feeling of a lack of knowledge about STIs. Topics that were less well known before the program were oral contraceptives, internal bimanual examinations, the uterine wall, and the female reproductive system [4]. Questions most often answered incorrectly on the post-test concerned Intrauterine device IUDs, ovulation cervical changes, and the menstrual cycles feedback system. The presentation of these topics should be improved. Knowledge of IUDs may be poor in part due to their uncommon use (ACHA, 2015).

According to the ACHA-NCHA (2009), 72\% of participants reported they were sexually active. The participants of this study's program, however, were less sexually active, with only $52.6 \%$ reporting sexually activity. Concerning gynecology, thirteen of the nineteen (68.2\%) educational program participants had been to the gynecologist. This result was slightly higher than the NCHA (2015) participants, as $42.4 \%$ of those participants had been to the gynecologist. The reason for these differences between the two study samples is undetermined [10].

\section{Limitations and Recommendations}

The use of convenience sampling and a small sample size were limitations. The study may have been improved with a control group and this is advised for future research studies. Healthcare providers may use this study to provide effective women's sexual health programs to the population. Most certainly additional research should be undertaken to identify the optimal methods for educating college age students as to their reproductive health.

\section{Summary}

Results of this descriptive design reinforced the understanding that this particular population was not as aware of the nuances of women's health care as would be desirable. In order to provide the self-care necessary, these students need to know more about themselves and the available health care options. Educational programs such as the program described need to be available to optimize the health of this group.

Conflicts of Interest: The author(s) report(s) no conflicts of interest.

Consent: No consent is required to our article publication.

\section{References}

1. American College Health Association National College Health Assessment (ACHA-NCHA). NCHA Web Summary. http://www.achancha.org/data/ SEXF06.html. Accessed May 23, 2016.

2. American College Health Association National College Health Assessment (ACHA-NCHA). NCHA Group Report. http://www.achancha. org/docs/ACHA-NCHA_Reference_Group_Report_Fall2009.pdf. Accessed May 23, 2016.

3. Paul E, McManusb B, Hayesb A. "Hookups": Characteristics and correlatos of collage students' spontaneous and anonymous sexual experiences. The Journal of Sex Research. 2010; 37(1): 76-88. doi: 10.1080/00224490009552023

4. American College Health Association National College Health Assessment (ACHA-NCHA). Fall 2015 Reference Group Executive Summary. http://www. acha-ncha.org/docs/NCHA-II\%20FALL\%202015\%20REFERENCE\%20 GROUP\%20EXECUTIVE\%20SUMMARY.pdf. Accessed May 23, 2016.

5. Caico C. Sexually risky behavior in college-aged students. Open Journal of Preventative Medicine. 2014; 4(5): 354-364. doi: 10.4236/ojpm.2014.45043

6. Ignatavicius $D$, Workman M. Medical-Surgical Nursing. Philadelphia: WB Saunders Company; 2009.

7. Lowdermilk D, Perry S. Maternity \& Women's Health Care. Saint Louis: Mosby; 2007.

8. Meaney G, Rye B, Wood E, Solovieva E. Satisfaction with school-based sexual health education in a sample of university student recently graduated from Ontario high schools. Canadian Journal of Human Sexuality. 2009; 18(3): 107-125.

9. Oster D. College students and sexual risk behavior. University of Rhode Island Digital Commons. http://digitalcommons.uri.edu/cgi/viewcontent. cgi?article $=1531 \&$ context=theses. Accessed May 23, 2016.

10. Wilson S, Giddens J. Health Assessment for Nursing Practice. Saint Louis Mosby; 2008. 